C2018, Elsevier. Licensed under the Creative Commons Attribution-NonCommercialNoDerivatives 4.0 International http://creativecommons.org/about/downloads

(9) $\odot \Theta \Theta$ 


\title{
An Assessment of UK Drivers' Attitudes Regarding the Forthcoming Ban on the Sale of Petrol and Diesel Vehicles
}

\begin{abstract}
The purpose of the study was to predict how drivers of petrol or diesel cars might vote in a 'Yes/No' referendum concerning the UK government's decision to ban from 2040 onwards the sale of all new non-electric vehicles. Five main factors were hypothesised to influence voting intention: a person's (i) level of environmental concern, (ii) attitude towards electric cars (measured via an Implicit Association Test), (iii) belief about the importance of air pollution, (iv) driving requirements, and (v) reaction to the cost of the ban to the individual (assessed using a contingency valuation approach). The study also examined possible determinants of attitudes to electric vehicles, e.g., whether an individual was a 'technology enthusiast', had prior knowledge of and searched for knowledge about electric vehicles, and whether a person had played an online game where the player assumed the identity of an electric car driver. A structural equation model was developed and tested on a sample of 675 UK drivers, none of whom had ever owned or driven an electric car. The results suggested a good fit of the model to the data, except that neither environmental concern nor belief in the importance of clean air affected attitude to electric cars. Also, high levels of environmental concern did not motivate people to search for knowledge about electric vehicles. Social marketing campaigns that will be needed to precede the ban should focus on its health benefits, and not target particular age groups, gender, or whether a participant had children.
\end{abstract}

Key words: electric vehicles; contingent valuation; environmental concern; implicit association test (IAT); technology enthusiasm; random utility model. 


\section{Introduction}

\subsection{Background}

On July $26^{\text {th }}, 2017$ the UK government announced that all sales of new petrol and diesel vehicles will be prohibited from $1^{\text {st }}$ January 2040 (DEFRA, 2017). After 2040, only electric vehicles (EVs) (or hybrids with 'near zero emissions') will be available on the UK new car market. The French government made the same commitment earlier in July 2017 (Asthana \& Taylor, 2017). To justify the ban, the UK government reported predictions that, by 2040 (i) around 40,000 UK residents (9,000 in London) will die annually because of air pollution, (ii) rising levels of nitrogen oxide will present the biggest single environmental risk to UK public health with respect to asthma, heart and lung disease, bronchitis, diabetes, autism, and several other major health problems, and (iii) up to $44 \%$ of UK wildlife habitats and half of all the country's plant life will be at risk from poor air quality. Moreover, diminished national productivity resulting from air pollution (currently estimated at $£ 2.7$ billion per year) is forecast to become worse.

Worldwide, air pollution is known to be a major cause of early death and, in the absence of 'aggressive intervention' the number of deaths due to ambient air pollution is estimated to increase by more than $50 \%$ by the year 2050 (Landrigan et al., 2017 p.4). Much of the problem is attributed to transport which, in 2015 , accounted for $17 \%$ of all global $\mathrm{CO}_{2}$ emissions (Bayram \& Tajer, 2017). Epidemiological studies have repeatedly identified consistent associations between air pollution and exacerbations of respiratory and cardiovascular illnesses (especially among older people); premature mortality and reduced quality of life (Castanas \& Kampa, 2008). Prior to 2040 the government will assume legal 
powers to enable state agencies to ensure that EV charge points are installed at all privatelyowned motorway service stations and other retail fuel outlets; will invest $£ 100$ million in developing the UK's EV charging infrastructure; and will compel local government authorities to introduce measures to facilitate the adoption of EVs (Asthana \& Taylor, 2017).

Those who oppose the plan note that the UK national electricity generating grid is likely to experience a $50 \%$ rise in early evening demand as drivers charge their EVs. Also, electricity imports will probably increase from their present level of $10 \%$ to possibly $33 \%$ (or more) of total supply (Swinford, 2017). Concerns have been raised, moreover, about the need not to undermine the automotive industry, which operates on the basis of long time cycles for major capital investment and will need many years to adopt the new policy (Hughes, 2017). Critics allege that electric cars are expensive and impractical (although technological improvements and mass production should reduce prices and improve EV reliability) and, to date, they have not been popular with the driving public (Bennett \& Vijaygopal, 2017). In 2016, only 10,264 new EVs and 26,643 new hybrids were sold in the UK out of a total of 2.69 million new car registrations (Lane, 2017).

Electric vehicles currently exhibit a number of drawbacks, including limited driving range, long charging times, paucity of recharging facilities, and relatively short car battery life (about five years) (see Egbue \& Long, 2012; Nie, Wang, Guo \& Shen, 2017 for further information on these matters). There is a view moreover that, from now on, battery and electric vehicle technology will accelerate naturally and rapidly so that by 2040 , combustible engine vehicles will have disappeared, so that government intervention will not be required (Johnston, 2017). At present, the position of the French and British governments is to outlaw 
specific types of combustion fuel vehicles rather than to aim for near-zero emissions from any type of vehicle.

\subsection{Objectives of the research}

So far, public opinion regarding the forthcoming ban is largely unknown. At the time of writing, the only pieces of information available were an on-line poll of 13,082 people reported in The Telegraph newspaper and a survey of 1078 readers of Consumer Intelligence magazine (Zuke, 2017), both completed in August 2017. The former indicated that $58 \%$ of the respondents opted for the statement 'No we should have the choice to buy whatever car we like'; as opposed to the statement 'Yes, it is vital we take these steps to battle pollution'. The latter found that $39 \%$ of the magazine's readers supported the future ban. Sixty-seven per cent stated that they worried about air pollution, although $70 \%$ were concerned about the cost of the ban to the taxpayer. Collateral information is available from a Forbes Magazine online survey of April 2017 which found that $70 \%$ of a sample of 157,000 mainly young readers did not want to buy electric cars. In 2016, the UK Department for Transport surveyed 1034 drivers finding that $16 \%$ had 'thought about buying an EV and decided against it'; just five per cent were 'thinking about' buying an EV (DfT, 2016).

To increase knowledge of UK drivers' likely attitudes towards the ban, the present research requested a sample of drivers drawn from the general driving public in England and Wales (none of whom had owned or driven an EVs) to state how they would vote (Yes or No) in a hypothetical referendum about the ban. Drivers were sampled as it is they who will be most affected by the ban's implementation. A model was constructed positing that attitudes regarding EVs (measured by an Implicit Association Test [IAT] - see Greenwald, McGhee \& 
Schwartz, 1998), plus certain other variables (see below), would affect voting intention. The study also explored possible determinants of attitudes towards EVs. As the investigation was based on a hypothetical referendum, i.e., on how people say they would vote rather than observing how they actually would vote, the research applied a random utility contingency valuation (RUCV) approach (McClelland, 2001) to the prediction of voting intention (see Hoyos \& Mariel, 2010; Vojacek \& Pecakova, 2010). Hence the participants were presented with a statement of a likely financial cost to them personally of implementing the ban (cf. Diamond \& Hausman, 1994); this cost being contingent on the participants obtaining the clean air benefits arising from the ban's application (cf. Fischoff \& Furby, 1988). (Following McClelland [2001], the costs specified in the present study were 1.5\%, 3\%, 4.5\%, $6 \%$ and 7.5\% of a person's income - see below for further details.) As all the previously mentioned costs arising from the ban will have to be recovered, each individual was randomly assigned to a particular income sacrifice category. Contingency valuation (CV) models are commonly employed to estimate economic values for environmental improvements (see Brookshire \& Crocker [1981]; King \& Mazzota [2016]; and TEC [2017] for details of CV methods, past uses, advantages and problems). Whilst participants' decisions in a CV study relate to hypothetical rather than real-life situations (so that the person making the choice does not actually have to bear the consequences), it is relevant to note that a study completed by Kirkvliet \& Vossler (2003) which compared hypothetical and actual voting in a public referendum, found no significant differences. A similar result was obtained by Vossler, Ethier, Poe \& Welsh (2003), although this investigation (of a 'green' electricity project) identified differing underlying distributions of consumers' willingness to pay for the project.

\subsubsection{Contributions of the present research}


Although contingency valuation models have been applied within several environmental research contexts, past studies have not examined connections between people's attitudes towards EVs and their willingness to pay for environmental improvements resulting from the widespread use of EVs. The present study addresses this gap in the research literature via an investigation of drivers' levels of support for environmental benefits resulting from the comprehensive adoption of EVs in terms of the income sacrifices necessary to achieve the benefits that will ensue. Previous investigations have surveyed public attitudes regarding EVs but have not related these attitudes simultaneously to study participants' direct experience of EVs (achieved in the present study in a virtual situation through some participants playing an EV-based game) and their concern for the environment. The current research questions not only whether drivers who exhibit high environmental concern also hold EVs in high esteem but also whether such individuals are willing to pay for the environmental gains attainable by banning the purchase of other types of vehicle. A further contribution of the study is the inclusion of 'technology enthusiasm' as a possible determinant of both favourable attitude regarding EVs and a person's search for knowledge about EVs. This issue is explored within a study of the impact of attitudes towards EVs on drivers' acceptance of a prohibition on the sale of vehicles other than EVs.

\section{Theoretical background and hypothesis development}

Conventionally the RUCV model is specified as: $\Delta U=\left[\mu_{1}(y-p, 1, Z)+\varepsilon_{1}\right]-\left[\mu_{0}(y, 0, Z)+\right.$ $\left.\varepsilon_{0}\right]$, where $\mu_{1}$ and $\mu_{0}$ are the observable components of a person's utility function for each state (denoted by $0 / 1$ depending, in the present study, on the presence or absence of the ban), and $\varepsilon$ is the unobserved, stochastic component of the function (see McClelland, 2001; Nie et al., 2017). The elements of $\mu_{1}$ and $\mu_{0}$ comprise the respondent's income (y); the value of the income sacrifice (p) needed to implement a new policy (i.e., the ban on non-electric vehicles 
in the current research) that is presented to the respondent in the referendum, plus (Z), i.e., the other sociodemographic, behavioural and variables state variables (described in later sections) that determine the utility. As all the factors affecting choice cannot be considered, the effects of the other factors are deemed to be incorporated in $\varepsilon$, the stochastic component. Operationalisation of the model requires a-priori selection of key characteristics of the participants in an investigation (Boxall \& Adamowicz, 2002) and, according to Nie et al. (2017), the consideration of interactions among specific variables.

Consequent to a literature review, the variables employed in the present study were (i) a person's attitude towards EVs, (ii) concern for the environment, (iii) whether a person was a 'technology enthusiast' (a high level of which was posited to trigger a search for knowledge about EVs), (iv) an individual's beliefs regarding the importance of air quality (itself affected by environmental concern), (v) a person's driving requirements (long or short journeys), (vi) relevant sociodemographic control variables (a driver's age, gender, education and income level and whether the person had children under age 16), (vii) a driver's prior knowledge of EVs, and (viii) the amount of income sacrifice that would induce an individual to vote 'no' in the referendum.

These variables were selected because many previous studies have found them to influence attitudes towards environmentally friendly products in general, and EVs in particular (for details see White \& Sintov [2017]). Also, the study uniquely considered the effects on attitudes towards EVs of whether a person had played a game that lasted for seven or eight minutes and was designed to introduce EVs to people who had never driven them. The game involved the individual assuming the role of an EV driver and being exposed virtually to the 
EV driving experience. The abovementioned variables and their hypothesised effects are described below.

\subsection{Attitude towards EVs}

A positive link between attitude towards EVs and intention to vote 'Yes' in a hypothetical referendum to ban combustible fuel vehicles could result from a driver's belief that EVs bestow substantial health benefits (OEERE, 2015; Tonachel, 2017), and/or that EVs offer excellent technical performance, represent a desirable futuristic technology, etc. (Egbue \& Long, 2012; Hutchins, Delmonte, Stannard, Evans \& Bussell, 2013; Bennett, Shaw \& Kottasz, 2016). 'No' voters, conversely, might be anticipated to regard EVs as not making significant contributions to public health, or not possessing extensive environmental benefits (e.g., due to the need for more coal burning power stations, cobalt and nickel mining, battery disposal facilities, etc. [Sanderson, 2017]). Equally, 'No' voters might dislike EVs due to their (present) disadvantages vis-à-vis their limited range, restricted availability of charging stations, long recharging durations, battery replacement costs, and so on (see Carley, Krause, Lane \& Graham, 2013). Accordingly, it is hypothesised that:

H1. Drivers possessing positive attitudes regarding EVs are more likely to vote 'Yes' in the hypothetical referendum.

A participant's attitude towards EVs lies at the heart of the model and is posited to be affected by the following considerations.

\subsubsection{Environmental concern}


Studies have demonstrated that environmental concern (defined by Franssonn and Garling [1999] as the self-evaluation of facts and of one's own and other people's attitudes and behaviour in relation to the environment), can positively and significantly influence attitudes towards EVs. According to Bamburg (2003), individuals who exhibit high levels of environmental concern tend to possess values and beliefs that trigger positive attitudes regarding environmentally-friendly products, such as EVs. Investigations of potential relationships between environmental concern and attitudes towards 'green' products in general have typically discovered a growing awareness among many consumers of the harm being done to the environment and hence that green products (e.g., electric vehicles) are beneficial (see Khaola, Potiane \& Mokheti, 2014). A survey conducted by Dogan and Ozmen (2017) found that concern for the environment exerted a strong influence on people's interest in EVs, especially when environmental concern was an important part of a person's selfidentity. Moreover, the expression of a favourable attitude towards EVs gives individuals opportunities to express to their valued peers their environmental responsibility (Ozaki \& Sevastyanova, 2011). This suggests:

H2. Drivers possessing high levels of concern for the physical environment are more likely to possess positive attitudes towards electric vehicles.

Independently of its influence on attitudes to EVs, environmental concern is posited to affect the likelihood of a 'Yes' vote in a referendum. A UK government survey of 3600 people found that, whilst $60 \%$ of the participants felt they knew little about environmental issues, most of the individuals sampled were 'aware and concerned about damage to the environment and wanted to do something about it', and believed that 'being green is now the socially acceptable norm' (Eccleston, 2007 p.1). Environmental concern has been found to depend significantly on a person's environmental values (Bamburg, 2003) and to have a heavy impact on environmentally-related intentions (Franssonn \& Garling, 1999). There is 
evidence indicating that consumers' attitudes vary substantially according to their views on the impact of products on the natural environment (Donaton \& Fitzgerald, 1992; Ottman, 2011), and that many consumers are willing to pay more for ecologically compatible products (Laroche et al., 2001). Thieme et al. (2015) found that environmental concern triggered actual behaviour with respect to sustainability; not just a 'willingness' to pay extra for green products. In the light of these considerations it is suggested that a 'Yes' vote in the hypothetical referendum will be more likely, ceteris paribus, to be obtained from a person with high environmental concern, on the grounds that such an individual will welcome the fact that banning combustible fuel vehicles will improve the environment.

H3. Drivers possessing high levels of concern for the physical environment are more likely to vote 'Yes' in the hypothetical referendum.

\subsubsection{Belief that air pollution represents a major health problem}

Most academic studies of public opinion about clean air (e.g., Stern, 2000; Clement, 2001) and results of public health campaigns (e.g., NICE, 2016) have shown that sentiments concerning clean air can substantially influence behaviour (as well as attitudes) involving the physical environment in general, and specifically the avoidance of air pollution. Nevertheless, research reported by Brekke, Howarth \& Nyborg (2006) indicated that beliefs about air pollution would only lead to behaviour that improves air quality among people who are motivated by strong internalised norms. Hence, Brekke et al. (2006) concluded, simply encouraging people to alter their behaviour related to air pollution would often be ineffective. A study completed by Stern (2000) also noted that deeply held personal feelings of obligation to engage in pro-environmental behaviour often determined the adoption of clean air practices. However, most people did not hold these deep feelings and thus most people would 
not be concerned by clean air issues. A further objection to the supposed beliefs-behaviour link, observed by Graham-Rowe et al. (2012) specifically in the EV context, was that whilst powerful beliefs could lead to positive attitudes towards the environmental benefits of EVs, an individual's personal mobility requirements could override these favourable sentiments. Prior investigations have concluded, moreover, that opinions about the consequences of air pollution vary widely according to study participants' political stance (see Davis, 2017), location, personal experiences and social and cultural background (Bickerstaff \& Walker, 2001; Anable, Lane \& Kaley, 2006). For operational purposes however, and because the ban on petrol and diesel vehicles will, ipso facto, improve air quality, it is hypothesised that:

H4. Drivers who believe that air pollution represents a major health problem are more likely to vote 'Yes' in the hypothetical referendum.

H5. Drivers who believe that air pollution represents a major health problem are likely to possess positive attitudes regarding EVs.

A priori it is reasonable to suppose that, ceteris paribus, high environmental concern will be associated with belief about the damaging effects of air pollution. Thus:

H6. High environmental concern is positively associated with the belief that air pollution represents a major health problem.

\subsubsection{Experience of playing an EV game}

The study hypothesises that a participant's attitude relating to EVs is affected by whether or not the person had previously played a game (created for the study by a commercial game development company) where the player drives a virtual EV on a simulated journey and, in the process, is exposed experientially to all key EV aspects. During the journey, the player 
receives and interacts with information about time to recharge, charge duration, vehicle performance (acceleration, etc.), fuel cost savings, vehicle range, and so on. Direct experience of an EV of this nature could be 'important in overcoming prejudices and convincing people that EVs are fun and convenient vehicles' (Schmalfus, Muhl \& Krems (2017). The game (i) introduces a person to a product not previously experienced (cf. Burke, 2014), (ii) stimulates curiosity about the product, and (iii) encourages emotional involvement with the product (Sailer, Hense, Mandel \& Klevers, 2013). Bennett and Vijaygopal (2017) found that drivers without experience of EVs who played a game involving EVs became significantly more favourably predisposed towards electric vehicles.

H7. Drivers who have played a game wherein the person adopts the identity of an EV driver are likely to have more positive attitudes towards EVs than people who have not played the game.

\subsubsection{Technology enthusiasm}

Enthusiasm for new technology is associated with (i) a liking for, and the early adoption of, technologically advanced products such as EVs, and (ii) self-confidence in their actual or hypothetical use (Egbue \& Long, 2012). Technology enthusiasts are opinion leaders vis-à-vis new innovations and actively seek information about the latest technological developments (Ozaki \& Sevastyanova, 2011). Individuals high in technology enthusiasm appreciate innovation for its own sake, are deeply interested in new ideas and, according to Slater and Mohr (2005), are motivated to become change agents within their reference groups. A number of studies concerning EVs have observed that technology enthusiasts will adopt EVs if these vehicles are seen as technically superior, often because EVs can act as symbols for people who wish to demonstrate an affinity with the latest technologies as part of their self- 
identity (e.g., Grewal, Mehta \& Kardes, 2000; Heffner, Kurani, \& Turrentine, 2007; Hahnel, Ortmann, Korcaj \& Spada, 2014). Electric vehicles project an image of technological innovation that may strongly influence adoption by technology enthusiasts (Grewal et al., 2000; White \& Sintov, 2017). It follows that technology enthusiasts are likely to hold positive attitudes towards EVs.

H8. Drivers who are technology enthusiasts are more likely to possess positive attitudes regarding electric vehicles than drivers who are low on technology enthusiasm.

Technology enthusiasm may trigger a search for knowledge about EVs, as might concern for the environment. Research has established that high environmental concern can motivate the search for knowledge about environmentally-friendly products (Minton \& Rose, 1997; Hansla, Gamble, Juliusson \& Garling, 2008). Environmentally concerned individuals may want to learn more about environmentally-friendly products (resulting in a search for information, see Laroche, Bergoron \& Babaro-Forleo [2001]), and the more the environmentally concerned learn the more likely that their attitudes regarding such products will be positive (Albayrak, Aksoy \& Caber, 2013). The cognitive effort devoted to information search may be substantial, and much attention might be paid to the environmental aspects of specific products (Franssonn \& Garling, 1999).

H9. Drivers who are technology enthusiasts are more likely to search for knowledge about EVs than are drivers who are low on technology enthusiasm.

H.10. Drivers who are high on environmental concern are more likely to search for knowledge about EVs than are drivers who are low on environmental concern. 


\subsubsection{Product knowledge}

Drivers who seek knowledge about EVs may be expected to possess more prior knowledge about EVs than others, and in principle this should influence their attitudes towards EVs. A substantial volume of literature has concluded that the decision-making processes of consumers with extensive product knowledge can differ substantially from the decision processes of individuals who have little product knowledge (see Park \& Moon, 2003; Tsai, Chang \& Ho, 2015). Survey data from several academic studies reported by Burgess, King, Harris, \& Lewis (2013) reported that attitudes concerning EVs among individuals without knowledge or experience of EVs tended to be less favourable than among people with knowledge of EVs. Consumer knowledge of EVs could arise from a person consciously seeking information, or from an individual's mere exposure to television or press advertisements, newspaper or magazine articles, or from conversations with other people (Le Hebel, Montpied \& Fontanieu, 2014). EV product knowledge may involve both rational and subjective elements (the latter sometimes arising from social norms [Moons \& De Pelsmacker, 2012; Rezvani, Jansson \& Bodin, 2015), and might not be based on objective facts. Nevertheless, regardless of its source or character, knowledge regarding EVs may constitute an important factor in consumer attitudes towards these vehicles (Egbue \& Long, 2012; Rezvani et al., 2015).

H11. Drivers who seek knowledge of EVs are likely to possess more prior knowledge about EVs than drivers who do not seek knowledge of EVs.

H12. Drivers who seek knowledge of EVs are likely to possess more favourable attitudes regarding EVs than drivers who do not seek knowledge of about EVs.

H13. High levels of prior knowledge of EVs are positively associated with favourable attitudes regarding EVs. 


\subsection{Driving requirements}

Intuitively it is reasonable to suppose that a driver who, at least occasionally, makes long journeys will be less favourably inclined towards EVs. Although many EVs are now capable of travelling distances sufficient for most purposes, and whilst each new generation of EVs significantly extends their driving range, studies have shown that current public perceptions of EV driving range is problematic and that many drivers believe that an EV's driving range will not be sufficient for their requirements. Among others, empirical studies undertaken by Burgess et al. (2013), Carley et al. (2013), Shaw, Bunce and Kottasz (2014) and Bennett et al. (2016) found that the perceived short driving range of EVs, in conjunction with the poor availability of charging points and slow charging processes, were regarded by the driving public as major disadvantages of electric vehicles. At present, charging point intensity is sparse in the UK and there is no common charging point system (these vary across several providers and each system requires its own subscription). The future intensity of charging points across the country is unknown. Assumptions that there will be a shortage of charging points could cause people who do have to make long journeys to believe that the ban will create inconvenience for them. Hence, such individuals may oppose the ban irrespective of their feelings concerning EVs.

H14. Drivers who, at least occasionally, make long journeys are more likely (a) to hold unfavourable attitudes towards EVs, and (b) to vote 'No' in the hypothetical referendum.

\subsection{Income sacrifice}

Implementation of the ban will be expensive. Every street and road in the country will have to be opened up to install charging points for on-street parked vehicles, public charging will 
have to be built and managed, road layouts may have to be altered (DEFRA, 2017), EV battery disposal facilities will be needed, power lines will have to be installed in every domestic garage, and so on. Importantly, the UK national grid will have to be greatly expanded and new power stations will have to be built. Additionally, and assuming that alternative funding mechanisms will not be implemented, the UK government will lose (at present prices) $£ 28$ billion a year in fuel tax. All this will cost the taxpayer a great deal, and taxpayers will be required to make income sacrifices to foot the bill. The full cost has not been estimated, but will be very large (Cox, 2017).

Higher levels of (assumed) income sacrifice might dissuade individuals from voting 'Yes' in the hypothetical referendum although a study of an air quality improvement plan in Bulgaria completed by McClelland (2001) found a substantial level of support for higher amounts of income sacrifice (nine to $12 \%$ of total income) among a sample of 243 taxpayers. The present study proposes that:

H15. Participants randomly assigned a high level of assumed income sacrifice needed to pay for the consequences of the ban are likely to vote 'No' in the hypothetical referendum.

Research has generally (but not always) shown positive connections to exist between a person's income level and willingness to pay for environmental quality (e.g., Shechter, Epstein \& Cohen, 1993; McConnell, 1997). A priori, high-income people might be expected to be more likely to vote 'Yes' as better-off individuals should be able to absorb income sacrifices more easily, regardless of the level of income sacrifice randomly allocated to them. Conversely, low income people may be more inclined to vote 'No' irrespective of the level of income sacrifice proposed, given their general shortage of money. Therefore, level of income 
might affect the relationship between the (exogenous) level of income sacrifice allocated to a participant and how the person would vote, i.e., wealthy people might show a greater propensity to vote 'Yes' at all levels of income sacrifice, and vice versa. Thus:

H16. Higher levels of drivers' incomes will positively moderate the connection between the level of income sacrifice allocated to individuals and the likelihood of their voting 'Yes' in the referendum, and vice versa.

\subsection{Control variables}

Bailey, Mishra and Tiamiyu (2016) observed how, in the past, environmentally concerned consumers often possessed a certain profile, i.e. they tended to be of high social status, had higher than average incomes, were younger and were better educated than the rest of the population. Bailey et al. (2016) noted however that this socio-demographic profile may have changed radically in recent years, consequent to more widespread publicity and more general public concern about the environment. Liere and Dunlop (1980) reviewed 21 studies that examined relationships between socio-demographic variables and environmental attitudes and behaviour, observing that these variables had achieved only limited explanatory success and rarely accounted for more than ten per cent of variation in dependent environmentally-related variables. Kolle and Thyavanahalli's (2016) extensive bibliometric study of global research on air pollution reached similar conclusions. A socio-demographic variable of particular interest in the present investigation is whether people with children under (say) age 16 will be more inclined to vote 'Yes' to the ban in order to enhance their children's future welfare (see Glazachev, 2007). The abovementioned control variables were included in the initial estimations of the model but, apart from level of income, no specific hypotheses are advanced regarding their likely significance or direction. 


\subsection{Interaction effects}

Stern (2000), Nie et al. (2017) and others (see Hines, Hungerford \& Tomera, 1987) have noted the complexity of public attitudes towards, environmental improvement and hence that studies should recognise possibilities for interactions among variables. The present research posits the presence of three moderating influences on the strength of the connection between a person having played the EV game and the individual's attitude towards EVs, as follows.

H17. The strength of the connection between the variable indicating whether or not a person had played the EV game and the variable measuring the person's attitude regarding EVs is moderated (a) positively by technology enthusiasm, (b) positively by prior knowledge of EVs, and (c) negatively by a person having to make long journeys.

\section{Research method}

The elements of the analysis consist of a main dependent variable (voting intention) that is posited to depend substantially on a number of antecedent variables; notably attitude towards EVs and the level of income sacrifice demanded of a participant, plus the other variables listed in the hypotheses stated above. Attitude to EVs lies at the core of the model and is itself assumed to depend in large part on a number of variables suggested by the extant literature that has examined the subject. Three of these variables, i.e., environmental concern, driving requirements (in the sense of at least occasionally having to make long journeys) and beliefs concerning air pollution, are also hypothesised to influence voting intention. An original feature of the present model is the proposition that people who played a game wherein they drove an EV in a simulated online environment would thereafter be more likely to hold more 
positive attitudes towards EVs than participants who had not played the game. Certain interconnections among the variables are presumed to exist, as described above. Collectively, hypotheses 1 to 17 make up a structural equation model that can be estimated in order to test the stated hypotheses.

The contingency valuation approach to the research was adopted for a number of reasons. Contingency valuation models permit the researcher to deal efficiently and effectively with phenomena that study participants have not previously experienced; are flexible in terms of the contingency to be manipulated (income sacrifice in the present investigation) and are based on people's own assessments of how much should be spent on an environmental improvement (rather than the cost being imposed by administrative command). In the present study it was possible, moreover, to present the participants with a clear and accurate description of the scenario associated with the discrete policy choice (Yes or No) under consideration. Participants were asked to accept or reject a specific policy at a given cost, and the mechanism by which payment would be made (i.e., through increased taxes) was stated. To execute the investigation an online questionnaire was developed, pretested, and then distributed online to 3000 members of the public recruited by a commercial data collection agency and selected from the agency's database as people who drive petrol/diesel vehicles in England and Wales. The pre-test was conducted via face-to-face administration to ten drivers approached at random in a street location in central London and asked to enter a University building to complete an Implicit Association Test to measure a person's attitudes regarding EVs, the game and the questionnaire. This enabled the researchers to identify any hesitations and confusions among the participants while completing the questionnaire, to measure the time taken and numbers of 'don't knows' recorded. Additionally, the contents of the 
questionnaire were discussed with two senior marketing academics and two local government experts in the transport field. As the study required participants to spend considerably more time on completing the questionnaire (plus the IAT and the EV game) than is normally the case in survey research (collectively the tasks required 20-25 minutes); a commercial data collection agency was employed to obtain responses for the main investigation from its panel of consumers who are willing to take part in surveys. The panel is periodically tested to ensure it matches the profile of the country as a whole. To avoid a poor response rate arising from people declining to complete the questionnaire or abandoning it half way through, the study applied a parsimonious approach to the document's construction. The primary aim of the investigation was to determine the study participants' voting intention on the basis of their attitudes to EVs, the level of income sacrifice required, environmental concern, driving requirements, and beliefs regarding the importance of air pollution. As the respondents' attitudes to EVs lay at the heart of the model (given that the hypothesised referendum related to the proposed ban on EVs), the second aim of the study was to examine the influences of variables that extant literature has found to constitute the main determinants of these attitudes. A new variable, whether a person had played an EV-based game, was added to the list of proposed determinants of attitudes to EVs. Certain inter-relationships among a number of variables were evident and, together with attitude to EVs, the independent and dependent variables constituted a structural equation model designed to explain voting intention. All the essential dimensions needed to examine voting intention were covered by the model which, for the reasons of parsimony and the avoidance of participant boredom and fatigue while completing the questionnaire, did not seek to explore further the possible determinants of the variables hypothesised to affect attitude to EVs. Belief in the importance of air pollution, for instance, is known to be affected by political opinions. Prior knowledge of EVs might depend 
in part on a person's cognitive ability and learning style. Such matters are peripheral to the major objective of the present study.

Six hundred and seventy-five individuals (all drivers without experience of EVs) agreed to participate. Half the sample members were asked to play the game and all were requested to complete the IAT online prior to answering the questionnaire. Participants who had been randomly selected to play the game were confronted online with a windscreen, through which the player virtually sees the road ahead. The person presses a key on a computer keyboard to start the vehicle and then virtually drives it through a built-up urban location, making left and right turns (activated by pressing relevant keys). The game lasts about eight minutes and includes a traffic jam, a diversion, and the need to negotiate around some road works. The player receives voice-over information during the game regarding time to recharging, charge duration, fuel cost savings, vehicle range, the performance advantages of EVs (fast and smooth acceleration, etc.), the government EV purchase subsidy, an EV's silent and comfortable running, easy controls, extra cabin space, and so on. Hence the game enabled players to experience EVs first-hand, thus impelling players to reassess their opinions about EVs.

The preamble to the questionnaire stated the alleged benefits of the ban in terms of lives saved, health improvements, preservation of wildlife and countryside environments, cleaner air and national reductions of oil imports. Each participant was randomly assigned to one of five income sacrifice categories $(1.5 \%, 3.0 \%, 4.5 \%, 6 \%, 7.5 \%)$ (i.e., 135 people per category) and informed that, because of the costs relating to the implementation of the ban (i.e., having to build additional electricity generating plant, payments to low income people to subsidise their having to pay higher electricity prices, costs of installing a national grid of charge points 
including the provision of plug-in equipment in every street in the country, and other costs detailed in official publications [see Contestabile et al., 2017; Cox, 2017; DEFRA, 2017]), the tax paid on a person's monthly income would increase in each of the next five years (the period normally required to build new power stations [Contestabile et al., 2017]) by the amount randomly assigned. The income sacrifice categories were determined via the 'passive use' variable selection method (see King \& Mazzota, 2016) whereby 150 members of the public were approached in various districts (some prosperous, some deprived, thus reflecting a wide range of sociodemographic characteristics as are likely to be found in the country as a whole) of Greater London and asked how much per month they would be prepared to pay to obtain clean air throughout the city. On average the respondents cited $£ 11$ per month (standard deviation $£ 4$ ) (an amount just more than a third of the monthly cost of a smartphone contract at the time the research was completed). Annualising this amount and expressing it as a percentage of the average amount of income tax paid, after allowances, by a UK citizen earning the national average wage, the average acceptable income sacrifice would represent an income tax rise of $4.5 \%$. Accordingly, $4.5 \%$ was used as the central figure for income sacrifice. (To avoid confusion the questionnaire stated the value of the income sacrifice in words rather than percentages, i.e., 'Because of the ban you will have to pay an extra $£ 1.50$ in tax on every $£ 100$ of your monthly income’, or ‘ - - - £3 in tax on every $£ 100$ of your monthly income, etc.) The questionnaire then asked for information on the abovementioned control variables and driving requirements (average weekly car mileage and types of journey undertaken [work, leisure, long holiday journeys]).

\subsection{Measurement of variables}


Environmental concern was measured via seven items adapted from Franssonn and Garling (1999) and Le Hebel, Montpied and Fontanieu (2014) which, when the participants' responses (seven-point agree/disagree scales) were factor analysed, indicated that item $2(\mathrm{~g})$ was an outlier. Removal of this item led to a unidimensional solution (Lambda=4.9; alpha=.87). Knowledge of EVs was assessed through four items based on Park and Lessig (1981) (Lambda=3.3, alpha=.89); beliefs concerning air pollution by four items adapted from Nie et al. (2017) (Lambda=3.4, alpha=.9); and technology enthusiasm by five items informed by Slater \& Mohr (2005) and Bennett et al. (2016) (Lambda=3.8; alpha=.89). The extent of an individual's search for knowledge of EVs was measured by three items informed by Laroche et al. (2001) $(\mathrm{R}=.89)$.

Attitude towards EVs lies at the centre of the model and was measured through an Implicit Association Test (IAT) (Greenwald et al., 1998) (set up using cognilab software) during which the participants were presented with words on a computer screen that they had to place into categories (by pressing 'i' or 'e' keys on a computer keyboard) associated with electric vehicles or with petrol/diesel cars. Strength of association in an IAT is evaluated by performance speed and accuracy as the respondent completes classification tasks; the faster the speed with which an item is categorised, the stronger the assumed association (for details of the procedure see Bennett \& Vijaygopal, 2017). On starting the IAT the participant saw two divisions (EV owners and Petrol Vehicle Owners) appearing at opposite ends of a computer screen. The person then categorised displayed examples of EVs and conventional vehicle models into one or other of the divisions. (IATs employ this initial procedure to focus the participant's thoughts on the two alternative kinds of entity.) Two possible descriptors (one positive and one negative) of each division then replaced the original divisions at each top corner of the computer screen and the individual had to categorise various examples of vehicle into either of the divisions. Next, different combinations of the 
positive and negative words and the positions of the categories appearing on-screen (left or right) replaced the previous divisions into which the person placed various types of vehicle. (Many free of charge examples of IATs and their method of construction are available online via the major Internet search engines.)

The words and phrases employed in the IAT (six with positive and six with negative connotations) were derived from a review of academic and practitioner literature and, in particular, Bennett et al's (2016) synthesis of themes embodied in manufacturers' and government promotional materials regarding EVs. Positive words and phrases were: economical, good for most types of journey, environmentally friendly, uses the latest technologies, excellent performance, and good for the public's health. Negative words and phrases were: costly, best only for certain types of journey, does little to improve the environment, technically conventional, unexceptional performance, does little to improve public health. IATs measure implicit as well as explicit attitudes by evaluating the strengths of connections between automatically made associations. (As an IAT requires instant judgements, participants cannot analyse information before responding, hence avoiding social responsibility bias, yet revealing potentially hidden prejudices [Devine, 1989].) The questionnaire is summarised in the Appendix to the paper.

\subsection{Estimation}

As configured in the previously stated hypotheses, the above variables comprise the elements of a structural equation model that contains several constructs (see the Appendix) with reflective indicators. Some of the variables in the model were not normally distributed, and since the objective of the analysis was to test hypotheses rather than to compare models, the 
model was estimated using the bootstrapping facility of the SmartPLS partial least squares package. (The PLS bootstrapping procedure generates standard errors that can be used for hypothesis testing in situations where variables are not normally distributed.) Partial least squares estimation is appropriate for predicting target non-normal variables within a complex structural model (Hair, Ringle and Sarstedt, 2012). All the variables were entered simultaneously into the initial estimation of the model. However, preliminary analysis showed that the control variables: participant's age, gender, education level, and whether a person had children under age 16 did not exert significant effects $(p>.4)$ on voting intention irrespective of any configuration of the other hypothesised independent variables. Hence these variables (which may have been insignificant due to people's experiences of bad air being common to both genders, all age groups, individuals with or without children, and all educational backgrounds) were removed from the estimation.

Diagnostics emerging from the estimation were satisfactory. Discriminant validity among the independent variables was adequate (all HTMT values <.62), and no substantial multicollinearity was observed (VIFs <.6 in all cases). The bivariate correlation between environmental concern and beliefs regarding the detrimental effects (or otherwise) of air pollution was significant $(\mathrm{R}=.53)$, but less than the value at which it would create technical difficulties with the estimation (Aiken \& West, 1991).

\section{Results}

Two hundred and seventy 'Yes' votes were recorded (40\% of the sample) and 403 'No' votes, an outcome broadly in line with newspaper and magazine surveys regarding this and related matters (see Eccleston, 2017; Koetsier, 2017; Zuke, 2017 - although these ad hoc surveys did not impose hypothetical costs). Most (60\%) of the participants in the present 
study opposed the forthcoming ban; suggesting that governments have much to do in order to change public attitudes regarding EVs and their capacity to improve drastically the quality of the physical environment. Further characteristics of the sample are shown in Table 1. Apart from the slight gender imbalance, the demographic figures cited are near to UK national averages. Most of the participants occasionally made long journeys. Only $14 \%$ of the responses fell on the top two divisions of the seven-point averaged scale for prior knowledge of EVs, and just $14 \%$ per cent of the sample members responded in the top two categories of the variable measuring belief that air pollution represents a major health problem. Sixteen per cent of the participants' replies fell in the top two divisions of the environmental concern variable. Twenty per cent of the respondents claimed to be technology enthusiasts. These results broadly match the outcomes to previous studies in relevant areas and suggest a general public ignorance of EVs in conjunction with somewhat nonchalant attitudes towards the physical environment. As regards income sacrifice, additional examination of the results data showed that there was some support for the ban even at the higher levels of personal cost. Eleven per cent of all the respondents assigned the highest amount of income sacrifice (i.e., $7.5 \%$ of income) stated they would vote 'Yes' to the ban. The percentage for the second highest sacrifice ( $6 \%$ of income) was $18 \%$, for the third $40 \%$, for the fourth $55 \%$, and for the lowest (1.5\% of income) $76 \%$. This indicates a recognition of the clean air issue among a considerable proportion of the driving public.

The results of the estimation of the structural equation model excluding the insignificant controls are given in Table 2. The headings in the ('Consequent') top row of Table 2 show the dependent variables relating to each of the hypotheses; the 'antecedent' column lists the explanatory variables within the model. The cells within the Table indicate the regression coefficients and bootstrapped T-values for each hypothesis. Thus, it can be seen from Table 2 
that, for example, voting intention was significantly influenced by attitude to EVs

(confirming H1), income sacrifice (H15), environmental concern (H3), driving requirements (H14b), and that the strength of the impact of income sacrifice on voting intention was affected by a person's level of income (H16). Attitude to EVs was significantly influenced by level of environmental concern, by whether a person had played the game, and by the other variables (including the three moderating effects) listed under the 'Attitude to EVs' heading. Interconnections among the variables in the model (beliefs about air pollution and environmental concern, etc.) were statistically significant as shown in Table 2 . The insignificance of age as a determinant of voting intention indicates that younger people were just as likely to support or oppose the ban as were older individuals. Air pollution, driving requirements, and environmental issues may well have affected the younger and the older participants approximately equally, leading to wide variations in data relationships involving the age variable. The same considerations apply to gender and level of education. As regards the insignificance of the variable measuring whether a participant had children under 16 , the result probably emerges from the fact that the median age of the sample members was 38 (almost the same as the national average of 39) and nearly half of the sample members had children under 16. Many more of the participants would have children just over age 16 or in older categories; so most of the sample members would have children. Hence there would be insufficient variation within the data to establish whether this variable had the capacity to influence other key variables. These results indicate that social marketing campaigns intended to engender support for the forthcoming ban do not need to target specific age groups, people of either gender, or individuals with or without children.

\section{Analysis}




\subsection{Tests of hypotheses}

Table 2 indicates that, as predicted, positive attitude towards EVs significantly influenced 'Yes' vote intention, confirming H1. Thus, if public attitudes towards EVs can be manipulated to favour EVs over petrol or diesel vehicles, e.g., by repeatedly pointing out the damage to health that combustion fuel vehicles cause, the easier it will become to create widespread acceptance of the forthcoming ban. It follows axiomatically that social marketing campaigns and general government promotional materials distributed in advance of the ban should portray convincingly the advantages of electric vehicles. Hypothesis 2 relating to the proposed connection between environmental concern and attitude towards EVs is rejected. Seemingly, therefore, many individuals possessing substantial degrees of environmental concern had low opinions of EVs. Given that positive attitude to EVs significantly affects 'Yes' vote intention, it is important that social marketing campaigns stress the environmental benefits of EVs in order to win over this influential category of voter to support widespread EV adoption. Nevertheless, people high on environmental concern were generally prepared to vote 'Yes' to the ban, irrespective of their reservations about the merits of EVs. Hypothesis 4 is rejected: beliefs that air pollution represents a major health problem did not translate into support for the ban. It is relevant to note in this connection that only $14 \%$ of the sample indicated a strong belief that air pollution was a matter that weighed heavily with them (as assessed via the items listed in the Appendix section 5), and there were no systematic patterns in the Appendix section 5 data. Likewise, H5 concerning the link of this variable with attitude to EVs, is rejected (again possibly because of negative views regarding EV performance). To address this apparent lack of interest in air quality, social marketing campaigns prior to the ban might perhaps overtly connect EVs to improvements in public health and to environmental protection, e.g., through advertisements that present images of people harmed or who died from air pollution related problems. References to natural disasters (floods, 
hurricanes, forest fires, etc.) potentially exacerbated by global warming could be employed to reinforce the impact of messages. The hypothesis that environmental concern is significantly linked to belief in the importance of clean air (H6) is accepted as expected. Environmental concern was positively associated with 'Yes' vote intention, so it would be clearly worthwhile for governments to invest in campaigns designed to link environmental concern, EVs, and issues relating to clean air, all together.

\subsubsection{Gamification}

Participants who played the game wherein they assumed the identity of an EV driver were significantly more likely to record favourable attitudes to EVs than people in the other half of the sample (H7). This demonstrates the value of gamification for arousing interest in and engagement with EVs, with consequent improvements in attitudes towards them (cf. McCarthy, Pitt, Robson \& Kietzmann, 2014). Harwood and Garry (2015) argued that gamification provides experiences which trigger emotions that induce positive attitudes and behaviours vis-à-vis a product that has been subjected to gamification. Importantly, in the present context, studies have found gamification to have valuable applications in social marketing (see Mitchell, Schuster \& Drennan [2017]). It seems, therefore, that EV-related games have much potential to foment favourable attitudes regarding EVs, and hence might be used as a valuable part of advertising campaigns aimed both at individual drivers and vehicle dealers.

\subsubsection{Technology enthusiasm and search for knowledge}

Hypotheses 8 and 9 regarding connections between technology enthusiasm and (i) attitude towards EVs, and (ii) search for knowledge about EVs, are accepted, as anticipated a-priori. 
However, H10 concerning the posited link from environmental concern to search for knowledge about EVs is rejected. It seems that people with high environmental concern did not necessarily want to search for knowledge about EVs, presumably because EVs were not held in high esteem. Government campaigns promoting EVs might seek to overcome this problem by making it easier to obtain knowledge about EVs. At present such knowledge tends to be hidden away in densely written technical reports published on central or local government websites (Bennett et al., 2016), or to be superficial as it appears in manufacturers' advertisements. The predicted association of search for knowledge with a higher level of prior knowledge of EVs (H11) is accepted. Also, individuals who bothered to search for knowledge about EVs had significantly better attitudes regarding them than people who did not search for knowledge (H12), presumably since the information they obtained engendered favourable attitudes. Hypothesis 13 is rejected: prior knowledge of EVs exerted a small and insignificant influence on attitude towards EVs. This may be the result of a considerable number of the participants having knowledge of EVs but disliking electric vehicles.

\subsubsection{Range anxiety}

Unsurprisingly perhaps, individuals who sometimes made long journeys tended to hold negative attitudes towards EVs (H14a),and also to oppose the introduction of the ban (H14b). 'Range anxiety' is known to be a major factor inducing dislike of EVs (see Shaw et al., 2014; Bennett et al., 2016). However, each new generation of EVs has a longer driving range than the one before and, by the time of the ban, technology should have advanced to the extent that battery range is no longer a problem. Thus, campaigns promoting EVs should detail their technical excellence, new features, technological advances, etc., and should actively seek to 
assuage fears arising from range anxiety. Messages relating to this will need to be promoted in publicity about the ban.

\subsubsection{Voting intention}

The strongest impacts on voting intention were attitude to EVs and driving requirements. Allocated income sacrifice level was in third place, exerting a negative influence on voting intention, as expected a-priori (H15). For many people, therefore, money was more important than environmental protection. Hence, there is a need for governments to explain to the public that essential environmental improvements have to be paid for, and that since all members of the public benefit from these improvements the fairest way of financing them is through taxation.

An important result for public policy however is that the moderating impact of level of income on voting intention was negative, indicating that the higher levels of income sacrifice (e.g., $5 \%$ and $7.5 \%$ ) allocated to wealthy people resulted in a greater propensity to vote 'No'. This might be due to the heavier financial burden placed on the wealthy by a percentage tax: $7.5 \%$ of an income of $£ 100,000$ is $£ 7,500$, whilst $7.5 \%$ of an income of $£ 20,000$ (just below the UK national average) is $£ 1,500$. An empirical study of 1,587 responses to the 'Giving in the Netherlands Panel Study' completed by Wiepking (2007) observed a similar outcome to an investigation of why the rich give proportionately less of their incomes to good causes than the poor. (In western countries the wealthy donate about $1 \%$ of annual income compared to around $3.5 \%$ for the poor.) Wiepking (2007) concluded that a certain 'giving standard' exists among wealthy people, i.e., they have in their minds a 'giving standard' regarding how much money, in absolute terms, they should donate. Critically, the giving standard of financially well-off people was found to be little higher than the giving standard of the poor. 
As regards the hypothesised moderators of the link between playing the game and attitude to EVs, driving requirements exerted a significant downwards influence on the strength of the connection (H17c) and technology enthusiasm had significantly positive impact (H17a), as anticipated. Prior knowledge had an insignificant effect (H17b), an unsurprising result considering the insignificance of the relation between prior knowledge and attitude.

\section{Conclusion and implications}

The present research has a number of implications, particularly for the social marketing campaigns that will need to precede the introduction of the ban. Within the context of an integrated structural equation model the study demonstrates the relevance of the random utility contingency valuation model for evaluating public opinion regarding the forthcoming ban. Uniquely, it employs an IAT to measure attitudes towards EVs and assesses the influence of game playing on these attitudes. Rezvani et al. (2015), in noting that most EV attitude research has been based on surveys unrelated to a participant's actual experience of EVs, called for alternative and more innovative methodological approaches to the assessment of EV attitudes. The current investigation answers this call and confirms the value of gamification for determining attitudes to EVs. A conceptual model was developed that, through providing insights into the antecedents and consequences of key variables with the potential to affect public opinion regarding the ban, can act as a foundation for future research in the area. The critical roles of environmental concern and attitudes to EVs as factors affecting the public's thoughts about the ban have been verified. 
The issue for public sector marketing is how to change attitudes regarding EVs and clean air rather than behaviour, as behaviour after 2040 has been prescribed. Many campaigns will be necessary to stimulate public support for the ban, and the testing of public opinion prior to the introduction of the ban will be essential if governments are to avoid voters in national elections favouring political parties that oppose the ban. Findings from the present study indicate that little will be gained from targeting pro-EV messages at specific age groups, a particular gender, or drivers with or without children or who possess disparate educational backgrounds. Instead, the results suggest that marketing messages should emphasise the health benefits of the ban, but not necessarily avoiding direct references to its (inevitable) costs given that $40 \%$ of the sample was (at least notionally) prepared to accept an income sacrifice to pay for the ban's implementation. Drivers' beliefs about whether air pollution represents a major health problem exerted little impact on voting intention. Thus, campaigns designed to create such beliefs are needed, repeatedly stating the numerous practical benefits to the public of clean air. The mass media has a crucial role to play in this respect, so positive interactions between government agencies and the mass media relating to the portrayal of issues connected with clean air are vital.

Gardiner (2014) argued that, despite the enormous detrimental impact of air pollution on public health, governments have in the past neglected clean air issues. At present, Gardiner (2014) observed, clean air activism is funded by private donations and occurs only at the grass roots level, mainly through Facebook and Twitter. Instead, Gardiner (2014) continued, government should take the lead and conspicuously promulgate smog warnings, publicise clean air health study reports, initiate clean air action days, etc., in order to engage the public with the issue. Corner and Randall (2011) analogously posited that the importance of clean air needs to be 'sold' to the public, e.g., through television stories about the horrific effects of 
air pollution, through 'drive fewer miles per week to reduce air pollution' campaigns, by appointing local 'clean air champions' and, critically, through introducing the subject of clean air into the school curriculum. The relevance of the connections between air pollution, petrol and diesel vehicles and people's lives must be made clear in public sector advertisements (see Peattie, Peattie and Ponting, 2009). It seems, moreover, that many of the participants had little regard for EVs. Marketing campaigns should therefore detail the technical excellence of this type of vehicle; their superior performance, comfort, etc., and should seek both to enhance drivers' feelings of self-efficacy vis-à-vis electric vehicles (Rezvani et al., 2005) and assuage doubts involving range anxiety. Media representations of leading politicians, sports personalities and celebrities prominently driving or being driven in EVs will be useful for achieving this aim. Games involving EVs can be produced and widely distributed to the driving public online as part of an advertising campaign (possibly accompanied by quizzes about EVs and EV driving cost calculators), or by offering a free download of an EV game to individuals entering car retailers' websites or car manufacturers' promotional websites, or through car dealer outlets (considering that a game can represent a virtual test drive). A variety of marketing communications devices is available for improving public perceptions of EVs, including materials that feature both the functional aspects of electric vehicles and their aesthetic qualities, plus measures designed to bring members of the public closer to EVs such as 'pop-up' EV information centres in shopping malls (as has been practised in Denmark and Germany) and attention-attracting mobile information centres that park in city streets (see Bennett \& Vijaygopal, 2017).

The finding that financially better-off people were unwilling to pay proportionately more towards the cost of implementing the ban has important implications for public policy, given that the ban will have to be paid for somehow: either through an amount included in 
percentage income tax levied on everyone, or through a levy imposed on drivers via a tax on every vehicle sold or an electricity charging tax, or through some sort of alternative tax to be paid by all citizens (e.g., an increase in value added tax). Option one might be unpopular with the wealthy, but option two would increase the prices and running costs of all vehicles sold from 2040 onwards and, considering that the majority of all new cars purchased in the UK are bought by businesses, the effect could be inflationary. Increases in value added tax are highly regressive and arguably unfair to the poor. Also, shoppers would be subsidising drivers. A future government will have to resolve this dilemma.

\subsection{Limitations and areas for future research}

Limitations of the study include the facts that (i) the hypothetical referendum was based on what the participants said they would do (predicated on 'pretend' rather than real income sacrifices) and not their actual voting behaviour, and (ii) the participants had no personal experience of the consequences of the proposed ban. Also, as with any IAT study, it was necessary to pre-specify particular characteristics of EVs and to test participants' views against this pre-specified benchmark. It would be valuable to repeat the study using different presumed EV characteristics, especially those related to aesthetic and emotional aspects. A further issue is the possibility that social desirability bias could have affected the results. However, the percentage of the items in the two variables with social desirability connotations (i.e., environmental concern and beliefs that air pollution represents a major health problem) to which the respondents gave possibly socially desirable responses was, at $23 \%$, insufficient to indicate the presence of bias of this nature. Also, the Implicit Association Test that measured attitudes to EVs, by its very character, avoided social desirability bias. Another potential difficulty is that some participants may have been so hostile to all the 
policies of the particular government in office at the time the research was completed, that they would oppose any and all proposals made by that government. In fact, pre-testing (see above) and analysis of the results indicated no evidence of 'nay saying' that might have resulted from political bias (or from other distortions potentially caused by individuals protesting about some other aspect of the given scenario). (The data collection company that was employed to collect responses vets its panel members to ensure they are not prone to answer questionnaires in socially desirable or otherwise distorted ways.) An alternative source of bias could arise from participants stating a positive willingness to pay in order to signal that they value environmental improvement in general, rather than the specific change covered by the study. Again, there was no evidence of 'yea saying' within the responses. It is relevant to note that contingency valuation studies completed by Johnstone (2006) and Vossler and Evans (2009) failed to find bias in hypothetical responses to stated choice referendums, although Johnstone (2006) observed that bias was possible in referendums where the issue under consideration was inconsequential to the voter.

The results show that drivers who make long journeys, even occasionally, tend to hold negative attitudes towards EVs, and previous research has frequently identified range anxiety as a major factor underlying drivers' reservations about EVs. Yet governments in a number of countries have publicly committed to rapidly and comprehensively improving charging infrastructures. In the UK for instance, the government in 2017 established a $£ 400$ million charging infrastructure fund, an extra $£ 100$ million in subsidies for installing plug-in facilities in households and businesses, and $£ 40$ million for charging systems research and development. Research is needed into public awareness of and receptivity to these initiatives, especially with respect to their impact (if any) on drivers' levels of range anxiety. Studies could determine which elements of charging structure enhancement could improve drivers' 
currently negative attitudes regarding EVs, e.g., standardised fittings, easy payment options, rapid recharges, locations of facilities in particular places.

Although environmental concern was significantly associated with beliefs that air pollution represents a major health problem, neither of these variables contributed significantly to positive attitudes to EVs. Also, environmentally concerned people were not motivated to search for knowledge about electric vehicles. Research is required to discover precisely why there is little connection between attitudes to environmental protection, beliefs regarding clean air, and electric cars. Connections should in principal exist given the clean air attributes of EVs. Possibly the environmentally concerned have a negative stereotype of electric vehicles and their drivers. If so, what are the key components of the negative stereotype and what are their determinants? Another area requiring additional research concerns the perceptions of the utility of the forthcoming ban held by buyers of fleet commercial vehicles. (Business purchases account for more than half of new car sales in Western Europe [Bennett, 2015].) Vehicles initially bought by businesses feed the second-hand car market. Therefore, if business buyers can be induced to begin using EVs in the near future, private buyers of second hand vehicles will be increasingly confronted with opportunities to own EVs, and their use will become widespread prior to the legislative ban in 2040.

Funding: This work was partially supported by the UK Department of Communities and Local Government and the European Commission as a component of the European Union Regional Development Fund Interreg IV project: XXXXX, grant number CCI XXXXXX. The European Commission financed the EV game and the collection of sections of the data used in the study. 
Table 1. Characteristics of the Sample

Gender (\% female) $\quad 46 \%$

$\begin{array}{ll}\text { Median age } & 38\end{array}$

$\%$ with a bachelor's degree or above $\quad 28 \%$

Median income $\quad £ 25.2 \mathrm{~K}$

$\begin{array}{ll}\text { Has children under age } 16(\%) & 42 \%\end{array}$

$\begin{array}{ll}\text { Undertakes long journeys at least occasionally (\%) } & 68 \%\end{array}$

Prior knowledge of EVs (\% in the two highest categories) $14 \%$

$\begin{array}{ll}\text { Search for knowledge about EVs }(\%) & 7 \%\end{array}$

Believes that air pollution represents a major health problem $(\%) \quad 14 \%$

$\begin{array}{ll}\text { Technology enthusiast (\%) } & 20 \%\end{array}$

$\begin{array}{ll}\text { Environmental concern }(\%) & 16 \%\end{array}$ 
Table 2. Parameter Estimates (Hypothesis Number, Regression Coefficient, and Tvalue)

\section{Consequent}

\begin{tabular}{|c|c|c|c|c|c|}
\hline & $\begin{array}{l}\text { Voting } \\
\text { intention }\end{array}$ & $\begin{array}{c}\text { Attitude to } \\
\text { EVs }\end{array}$ & $\begin{array}{c}\text { Beliefs } \\
\text { concerning } \\
\text { air } \\
\text { pollution }\end{array}$ & $\begin{array}{c}\text { Prior } \\
\text { Knowledge }\end{array}$ & $\begin{array}{l}\text { Search for } \\
\text { knowledge }\end{array}$ \\
\hline Attitude to EVs & $\begin{array}{r}\text { H1: } 0.39 \\
(4.27) \\
\end{array}$ & & & & \\
\hline $\begin{array}{l}\text { Income sacrifice level } \\
\text { allocated }\end{array}$ & $\begin{array}{l}\text { H15: } \\
\quad-0.28 \\
(3.21)\end{array}$ & & & & \\
\hline $\begin{array}{l}\text { Environmental } \\
\text { concern }\end{array}$ & $\begin{array}{r}\text { H3: } 0.31 \\
(3.44) \\
\end{array}$ & $\begin{array}{r}\text { H2: } 0.09 \\
(1.15) \\
\end{array}$ & $\begin{array}{r}\text { H6: } 0.40 \\
(3.82) \\
\end{array}$ & & $\begin{array}{r}\text { H10: } 0.13 \\
(1.29) \\
\end{array}$ \\
\hline $\begin{array}{l}\text { Has/has not played } \\
\text { the game }\end{array}$ & & $\begin{array}{r}\text { H7: } 0.28 \\
(3.34) \\
\end{array}$ & & & \\
\hline Driving requirements & $\begin{array}{r}\text { H14b: } \\
-0.45 \\
(5.04)\end{array}$ & $\begin{array}{r}\text { H14a: } \\
-0.29 \\
(2.44)\end{array}$ & & & \\
\hline Prior knowledge & & $\begin{array}{r}\text { H13: } 0.06 \\
(0.09)\end{array}$ & & & \\
\hline Search for knowledge & & $\begin{array}{r}\text { H12: } 0.28 \\
(2.36)\end{array}$ & & $\begin{array}{r}\text { H11: } 0.33 \\
(3.01) \\
\end{array}$ & \\
\hline $\begin{array}{l}\text { Technology } \\
\text { enthusiasm }\end{array}$ & & H8: $\begin{array}{r}0.41 \\
(3.98) \\
\end{array}$ & & & $\begin{array}{r}\text { H9: } 0.40 \\
(4.35) \\
\end{array}$ \\
\hline $\begin{array}{l}\text { Beliefs concerning air } \\
\text { pollution }\end{array}$ & $\begin{array}{r}\text { H4: } 0.11 \\
(1.27)\end{array}$ & H5: $\begin{array}{r}0.09 \\
(0.08)\end{array}$ & & & \\
\hline $\begin{array}{l}\text { Level of income times } \\
\text { Income sacrifice level } \\
\text { allocated (moderator) }\end{array}$ & $\begin{array}{r}\text { H16: } \\
-0.025 \\
(2.88)\end{array}$ & & & & \\
\hline \multicolumn{6}{|c|}{ Moderators affecting the influence of having played the game } \\
\hline Driving requirements & & $\begin{array}{r}\boldsymbol{H 1 7} \text { (c): } \\
0.022 \\
(3.69)\end{array}$ & & & \\
\hline Prior knowledge & & $\begin{array}{c}\boldsymbol{H 1 7} \text { (b): } \\
0.001 \\
(1.34) \\
\end{array}$ & & & \\
\hline $\begin{array}{l}\text { Technology } \\
\text { enthusiasm }\end{array}$ & & $\begin{array}{r}H 17 \text { (a): } \\
0.032 \\
(4.44)\end{array}$ & & & \\
\hline
\end{tabular}

$F(6,669)=5.58 \quad F(9,669)=4.95 \quad F(1,669)=12.7 \quad F(1,669)=8.17 \quad F(2,669)=4.08$ 


\section{APPENDIX. THE QUESTIONNAIRE}

The questionnaire began by asking the respondents how they would vote given that implementation of the ban would mean that their total annual tax payment would increase by the amount specified. The questionnaire then proceeded as follows.

1. Personal characteristics: gender, age and income categories; household structure (number of children); types of journey (whether long as well as short journeys were undertaken); highest educational qualification.

\section{Environmental concern}

(a) People worry too much about human progress harming the environment.

(b) People need to change their lifestyles to protect the environment.

(c) Environmental problems have been greatly exaggerated.

(d) I am a person who does what is right for the environment, even when it takes more time or costs more money.

(e) Environmental protection is simply a waste of money.

(f) We need to be proactive in protecting the environment as we cannot rely on modern technology to solve environmental problems.

(g) Threats to the environment are not my business.

\section{EV product knowledge}

(a) I have little knowledge of electric vehicles.

(b) I have not read or seen much information about electric vehicles.

(c) I am not familiar with electric vehicles.

(d) I am largely ignorant of EVs. 


\section{Search for knowledge about EVs}

(a) Whenever I come across a magazine or newspaper article or internet item about electric vehicles I am always keen to read it.

(b) I will actively look for information about developments concerning electric vehicles.

(c) I try my best to learn as much as possible about electric vehicles.

5. Beliefs that air pollution represents a major health problem

(a) I have little or no fear that problems to do with polluted air will an impact on myself or my family's health.

(b) Issues to do with air pollution never bother me because I think that clean air problems are overestimated.

(c) Air pollution represents a major health problem.

(d) The effects of air pollution on public health are overrated

\section{Technology enthusiasm}

(a) I see myself as being a pioneer where new technologies are concerned.

(b) I am a true enthusiast where new technology is concerned.

(c) I am a person who is always happy to experience new things.

(d) I always feel self-confident when faced with a new technology.

(e) I am a person who appreciates innovation for its own sake. 


\section{References}

Aiken, L. \& West, S. (1991). Multiple regression: Testing and interpreting interactions. Newbury Park, CA: Sage.

Albayrak, T., Aksay, S. \& Caber, M. (2013). The effect of environmental concern and scepticism on green purchase behaviour. Marketing Intelligence and Planning, 31 (1), 27-39. Anable, J., Lane, B. \& Kelay, T. (2006). An evidence-based review of public attitudes to climate change and transport behaviour. London: Department of Transport. Retrieved from www.fcm.org.uk. (Last accessed: 31 August 2017.)

Asthana, A. \& Taylor, M. (2017). Britain to ban sale of all diesel and petrol cars and vans from 2040. The Guardian, 25 July 2017. Retrieved from www.theguardian.com. (Last accessed: 21 August, 2017.)

Bailey, A., Mishra, A. \& Tiamiyu, M. (2016). Green advertising receptivity: An initial scale development process. Journal of Marketing Communications, 22 (3), 327-345.

Bamburg, S. (2003). How does environmental concern influence specific environmentally related behaviour? A new answer to an old question, Journal of Environmental Psychology, $23(1), 21-32$.

Bayram, I. \& Tajer, A. (2017). Plug-in electric vehicle grid integration. Norwood MA: Artech House.

Bennett, R. (2015). Fleet buyers' intentions to purchase electric vehicles: Antecedents and possible consequences. International Journal of Electric and Hybrid Vehicles, 7 (4), 362-374. Bennett, R., Shaw, S. \& Kottasz, R. (2016). Factors potentially affecting the successful promotion of electric vehicles. Journal of Social Marketing, 6 (1), 62-82.

Bennett, R. \& Vijaygopal, R. (2017). Consumer attitudes towards electric vehicles: Effects of product user stereotype and self-image congruence, European Journal of Marketing. In press. 
Bickerstaff, K. \& Walker, G. (2001). Public understandings of air pollution: The 'localisation' of environmental risk. Global Environmental Change, 11, 133-145.

Boxall, P. \& Adamowicz, (2002). Understanding heterogeneous preferences in random utility models: A latent class approach. Environmental and Resource Economics, 23, 421-446. Brekke, A., Howarth, R. \& Nyborg, K. (2006). Green consumers and public policy: On socially contingent moral motivation. Resource and Energy Economics, 28 (4), 351-366. Brookshire, D. \& Crocker, T. (1981). The advantages of contingency valuation methods for benefit-cost analysis. Public Choice, 36 (2), 235-252.

Burgess, M., King, N., Harris, M. \& Lewis, E. (2013). Electric vehicle drivers' reported interactions with the public: Driving stereotype change? Transportation Research F, 17, 3344.

Burke, B. (2014). Gamify: How gamification motivates people to do extraordinary things. Brookline MA: Bibliomotion.

Carley, S., Krause, R., Lane, B. \& Graham, J. (2013). Intent to purchase a plug-in electric vehicle: A survey of early impressions in large US cites. Transportation Research D, (18), 39- 45.

Castanas, E. \& Kampa, M. (2008). Human health effects of air pollution. Environmental Pollution, 151, (2) 326-367.

Clement, D. (2001). Cost versus benefit: Clearing the air? Minneapolis: Federal Reserve Bank of Minneapolis. Retrieved from www.minneapolisfed.org. (Last accessed: 31 August 2017.)

Contestabile, M., Alajaji, M. \& Almubarak, B. (2017). Will current electric vehicle policy lead to cost-effective electrification of passenger air transport? Energy Policy, 110, 20-30. 
Corner, A. \& Randall, A. (2011). Selling climate change? The limitations of social marketing as a strategy for climate change public engagement. Global Environmental Change, 21 (3), 1005-1014.

Cox, J. (2017). Diesel and petrol car ban by 2040 would cost consumer and economy trillions, campaign group warns. The Independent, 26 July 2017. Retrieved from www.theindependent.co.uk. (Last accessed 8 December 2017.)

Davis, N. (2017). 65\% of British public support new Clean Air Act says survey. The Guardian, 14 February 2017. Retrieved from www.theguardian.com. (Last accessed: 31 August 2017.)

DEFRA (Department for Environment, Food and Rural Affairs) (2017). UK plan for tackling roadside nitrogen dioxide concentrations: An overview. London: The Stationery Office. Devine, P. (1989). Stereotypes and prejudice: Their automatic and controlled components. Journal of Personality and Social Psychology, 56 (1), 5-18.

DfT (Department of Transport) (2016). Public attitudes towards electric vehicles: 2016 revised. London: Department for Transport.

Diamond, P. \& Hausman, J. (1994). Contingent valuation: Is some number better than no number. Journal of Economic Perspectives, 8 (4), 45-64.

Dogan, V. \& Ozmen, M. (2017). Belief in environmentalism and independent-interdependent self-construal as factors predicting interest in and intention to purchase hybrid electric vehicles. Current Psychology, in press website.

Donaton, S. \& Fitzerald, K. (1992). Polls show ecological concern is strong. Advertising Age, 63, p3.

Eccleston, P. (2007). Public concerned on environment, survey says. The Telegraph, 2 November 2007. Retrieved from www.telegraph.co.uk. (Last accessed: 12 October 2016.) 
Egbue, O. \& Long, S. (2012). Barriers to widespread adoption of electric vehicles: An analysis of consumer attitudes and perceptions. Energy Policy, 48, 717-729.

Fischoff, B. \& Furby, L. (1988). Measuring values: A conceptual framework for interpreting transactions with special reference to contingent valuation of visibility. Journal of Risk and Uncertainty, 1, 147-184.

Franssonn, N. \& Garling, T. (1999), Environmental concern: Conceptual definitions, measurement methods, and research findings, Journal of Environmental Psychology, 19, 369382.

Gardiner, B. (2014). Air of revolution: How activists and social media scrutinise air pollution. The Guardian 31 January 2014. Retrieved from www.theguardian.com. (Last accessed: 27 November 2017.)

Glazachev, O. (2007). Into thin air: Training children to live in polluted environments. In M. Edelstein, M. Tysiachniouk \& L. Smirnova (Eds), Cultures of Contamination: Research in Social Problems and Public Policy, Vol. 14, pp. 373-389. Bradford: Emerald.

Graham-Rowe, E., Gardner, B., Abraham, C., Skippon, S., Dittmar, H., Hutchins, R. \& Stannard, J. (2012). Mainstream consumers driving plug-in hybrid electric cars: A qualitative evaluation of responses and evaluations. Transportation Research A, 46, 140-153.

Greenwald, A., McGhee, D. \& Schwartz, J. (1998). Measuring implicit differences in individual cognition: The Implicit Association Test. Journal of Personality and Social Psychology, 74, 1464-1480.

Grewal, R., Mehta, R. \& Kardes, F. (2000). The role of the social identity function of attitudes in consumer innovativeness and opinion leadership. Journal of Economic Psychology, 21, 233-252.

Hair, J., Ringle, C. and Sarstedt, M. (2012). Partial least squares: The better approach to structural equation modelling? Long Range Planning, 45 (5/6), 312-319. 
Hahnel, U., Ortmann, C., Korcaj, L. \& Spada, H. (2014). What is green worth to you? Activating environmental values lowers price sensitivity towards electric vehicles. Journal of Environmental Psychology, 40, 306-319.

Hansla, A., Gamble, A., Juliusson, A. \& Garling, T. (2008). The relationships between awareness of consequences, environmental concern, and value orientations. Journal of Environmental Psychology, 28 (1), 1-9.

Harwood, T. \& Garry, T. (2015). Gamification as a customer engagement experience. Journal of Services Marketing, 29 (6/7), 533-546.

Heffner, R., Kurani, K. \& Turrentine, T. (2007). Symbolism in California's early market for hybrid electric vehicles. Transportation Research D, 12, 398-413.

Hoyos, D. \& Mariel, P. (2010). Contingent valuation theory: Past, present and future. Prague Economic Papers, 4, 329-343.

Hines, J., Hungerford, A. \& Tomera, A. (1987). Analysis and synthesis of research on responsible environmental behaviour: A meta-analysis. Journal of Environmental Education, $18(2), 1-8$.

Hughes, L. (2017). Critics warn diesel ban could cost trillions. The Telegraph, 26 July 2017. Retrieved from www.telelegraph.co.uk. (Last accessed: 24 October 2017.)

Hutchins, R., Delmonte, E., Stannard, J., Evans, L. \& Bussell, S. (2013). Assessing the role of the Plug-in Car Grant and Plugged-in Places Scheme in electric vehicle take-up. London: Transport Research Laboratory. Johnston, I. (2017). Why the government's plan to ban petrol and diesel cars may not achieve anything. The Independent, 26 July 2017. (Retrieved from www.independent.co.uk. (Last accessed: 26 July 2017.) 
Johnstone, R. (2006). Is hypothetical bias universal? Validating contingent valuation responses using a binding public referendum. Journal of Environmental Economics and Management, 52 (1), 469-481.

Kerkvliet, J. \& Vossler, C. (2003). A criterion validity test of the contingent valuation method: Comparing hypothetical and actual voting behaviour for a public referendum. Journal of Environmental Economics and Management, 45 (3), 631-649.

Khaola, P., Potiane, B. \& Makhethi, M. (2014). Environmental concern, attitude towards green products and purchase intentions in Lesotho. Ethiopian Journal of Environmental Studies and Management, 7 (4), 361-370.

King, D. \& Mazzota, M. (2016). Ecosystem valuation; Contingency valuation method. Washington DC: US Department of Agriculture. Retrieved from www.ecosystem.org. (Last accessed: 17 October 2017.)

Koetsier, J. (2017). Surprise: $70 \%$ of millennials do not want electric vehicles. Forbes Magazine, 27April 2017. Retrieved from www.forbes.com. (Last accessed: 23 October 2017.)

Kolle, S. \& Thyavanahalli, S. (2016). Global research on air pollution between 2005 and 2014: A bibliometric study. Collection Building, 35 (3), 84-92. Landrigan, P. et al. (2017). The Lancet Commission on Pollution and Health. London: The Lancet. Retrieved from www.thelancet.com. (Last accessed: 23 October 2017.) Lane, B. (2017). Electric car market statistics. Bristol: Next Green Car. Retrieved from www.nextgreencar.com. (Last accessed: 25 August 2017.) Laroche, M., Bergerson, J. \& Babaro-Forleo, G. (2001), Targeting consumers who are willing to pay more for environmentally friendly products. Journal of Consumer Marketing, 18 (6), 503-520. 
Le Hebel, F., Montpied, P. \& Fontanieu, V. (2014). What can influence students' environmental attitudes? Results from a study of 15-year-old students in France. International Journal of Environmental and Science Education, 9, 329-345.

Liere, K. \& Dunlop, R. (1980). The social bases of environmental concern: A review of hypotheses, explanations and empirical evidence. Public Opinion Quarterly, 44 (2), 181-197. McClelland, E. (2001). Measurement issues and validity tests for using attitude indicators in contingent valuation research. Working Paper \# 01-01, November 2001. Washington DC: US Environmental Protection Agency. Retrieved from www.epa.gov. (Last accessed: 25 August 2017.)

McCarthy, I., Pitt, L., Robson, K. \& Kietzmann, J. (2014). Understanding the gamification of consumer experiences. Advances in Consumer Research, 42, 352-356.

McConnell, K. (1997). Income and the demand for environmental quality. Environmental and Developmental Economics, 2 (4), 383-399.

Minton, A. \& Rose, R. (1997). The effects of environmental concern on environmentally friendly behaviour: An exploratory study. Journal of Business Research, 40 (1), 37-48. Mitchell, R., Schuster, L. \& Drennan, J. (2017). Understanding how gamification influences behaviour in social marketing. Australasian Marketing Journal, 25 (1), 12-19.

Moons, I. \& De Pelsmacker, P. (2012). Emotions as determinants of electric car usage intention. Journal of Marketing Management, 28 (3/4), 195-237.

NICE (National Institute for Health and Care Excellence) (2016). Transport related air pollution: Draft December 2016. Manchester: NICE.

Nie, Y., Wang, E. Guo, Q. \& Shen, J. (2017). Examining Shanghai consumer preferences for electric vehicles and their attributes. Discussion Paper, Research Institute for Economics and Business Administration. Kobe: Kobe University. Retrieved from www.rieb.kobe. (Last accessed: 23 October 2017.) 
OEERE (Office of Energy Efficiency and Renewable Energy) (2015). Reducing pollution with electric vehicles. Washington DC: OEERE. Retrieved from https//:energy.gov. (Last accessed 26 October 2017.)

Ottman, J. (2011). The new rules of green marketing: Strategies, tools, and inspirations for sustainable branding. London: Greenleaf Publishing.

Ozaki, R. \& Sevastyanova, K. (2011). Going hybrid: An analysis of consumer purchase motivations. Energy Policy, 39 (5), 2217-2227.

Park, C. \& Lessig, V. (1991). Familiarity and its impact on consumer decision biases and heuristics. Journal of Consumer Research, 8 (3), 223-230.

Park, C. \& Moon, B. (2003). The relationship between product involvement and product knowledge. Psychology and Marketing, 20 (11), 977-989.

Peattie, K., Peattie, S. \& Ponting, C. (2009). Climate change: A social and commercial marketing communication challenge. EuroMed Journal of Business, 4 (3), 270-286.

Rezvani, Z., Jansson, J. \& Bodin, J. (2015). Advances in consumer vehicle adoption research: A review and research agenda. Transportation Research D, 34, 122-136.

Sailer, M., Hense, J., Mandl, H. \& Klevers, M. (2013). Psychological perspectives on motivation through gamification. Interaction Design and Architecture Journal, 19 (1), 28-37. Sanderson, H. (2017). Electric car growth sparks environmental concerns. Financial Times 7 July 2017. Retrieved from www.ft.com . (Last accessed: 26 October 2017.) Shaw, S., Bunce, L. \& Kottasz, R. (2014). Report to inform the setting up of Regional Emobility Information Centres. (E-mobility NSR Report). Retrieved from http://www.northsearegion.eu/ivb/projects/details/\&tid=133. (Last accessed: 14 August 2016). 
Schmalfus, F., Muhl, K. \& Krems, J. (2017). Direct experience with battery electric vehicles matters evaluating vehicle attributes, attitude and purchase intention. Transportation Research F, 46A, 47-69.

Shechter, M., Epstein, L. \& Cohen, A. (1993). Air pollution and health: Economic and epidemiological aspects. Environmental Management and Health, 4 (1), 6-15.

Slater, S. \& Mohr, J. (2005). Successful development and commercialisation of technological innovations: Insights based on strategy type. Journal of Product Innovation Management, 23 (1), 26-33.

Stern, P. (2000). New environmental theories: Toward a coherent theory of environmentally significant behaviour. Journal of Social Issues, 56 (3), 407-424.

Swinford, S. (2017). Diesel and petrol car ban: Plan for 2040 unravels as 10 new power stations needed to cope with electric revolution. The Telegraph, 27 July 2017. Retrieved from www.the telegraph.com. (Last accessed: 21 August 2017.) TEC (Transportation Economics Committee) (2017). Transportation benefit-cost analysis: Contingent valuation. California: University of California at Berkeley. Retrieved from http//: bca.transportationeconomics.org. (Last accessed: 17 October 2017.)

Thieme, J., Rayne, M., Jha, S., Levy, M. \& McEntee, W. (2015). Factors affecting the relationship between environmental concern and behaviours. Marketing Intelligence and Planning, 33 (5), 675-690.

Tonachel, L. (2017). Environmental assessment of full electric transportation portfolio. Palo Alto CA: Electric Power Research Institute. Retrieved from www.epri.com. (Last accessed: 26 October 2017.)

Tsai, Y., Chang, H. \& Ho, K. (2015). A study of the relationship among brand experiences, self-concept congruence, customer satisfaction, and brand preference. Contemporary Management Research, 11 (2), 97-116. 
Vojacek, O. \& Pecakova, I. (2010). Comparison of discrete choice models for economic environmental research. Prague Economic Papers, 1, 35-53.

Vossler, C., Ethier, R., Poe, G. \& Welsh, M. (2003). Payment certainty in discrete choice contingent valuation response: Results from a field experiment. Southern Economic Journal, 69 (4), 886-902.

Vossler, C. \& Evans, M. (2009). Bridging the gap between the field and the lab:

Environmental goods, policy maker input, and consequentiality, Journal of Environmental Economics and Management, 58 (3), 338-345.

White, L \& Sintov, N. (2017). You are what you drive: Environmentalist and social innovator symbolism drives electric vehicle adoption intentions. Transportation Research A, 99, 94113.

Wiepking, P. (2007). The philanthropic poor: In search of explanations for the relative generosity of lower income households. Voluntas, 18, 339-358.

Zuke, E. (2017). Public support grows for petrol and diesel ban with half of consumers considering electric vehicles. Consumer Intelligence 7 August 2017. Retrieved from www.consumerintelligence.com. (Last accessed: 23 October 2017.) 